\title{
Brasil, África, Portugal: da política externa independente à CPLP
}

\author{
Cláudio Oliveira Ribeiro
}

\section{Resumo}

Este artigo tem como propósito dar prosseguimento aos trabalhos de pesquisa e análise sobre a política externa brasileira, iniciados em um aperfeiçoamento entre 1999 e 2000 e desenvolvidos durante o mestrado no Departamento de Ciência Política da USP, em 2002, com apoio da Global Fundation for Research and Scholarship e da Comissão de Cooperação Internacional da USP.

Nesta nova etapa, o objetivo principal consiste em traçar um esboço das relações diplomáticas do Brasil com a África e Portugal. Para tanto, pretende-se focalizar o desenvolvimento da política externa brasileira desde a década de sessenta até a de noventa, procurando investigar o posicionamento do Estado Brasileiro diante dos processos de constituição e evolução da CPLP, com relevância para a triangulação diplomática estabelecida entre Brasil, África Portuguesa e Portugal.

A Comunidade de Países de Língua Portuguesa - CPLP foi oficialmente criada em 17 de julho de 1996 pela congregação dos sete países do globo que têm o português como língua oficial - Angola, Brasil, Cabo Verde, Guiné-Bissau, Moçambique, Portugal e São Tomé e Príncipe, registrando-se a inclusão do Timor Leste em 2002. ${ }^{1}$ Para

1 Inicialmente, o Timor Leste era observador convidado da CPLP, devendo se tornar membro pleno assim que completasse a transição para a independência, ini- 
além da identidade lingüística, ${ }^{2}$ a CPLP envolve aspectos político-diplomáticos de cooperação econômica, social, cultural, jurídica e técnico-científica. Neste sentido, a ação diplomática brasileira para a CPLP constitui um importante referencial para a avaliação da conduta externa do país e suas possibilidades frente ao sistema internacional contemporâneo.

A triangulação hoje institucionalizada pela CPLP possui raízes históricas que remontam ao passado colonial de intensas trocas estabelecidas entre Portugal, Brasil e África. ${ }^{3}$ Estas raízes são identificadas tanto na composição racial quanto nas composições cultural e política do Brasil, através do grande contingente populacional e pela herança cultural e institucional herdada de Portugal e da África.

No que tange às relações diplomáticas propriamente ditas, entre o período que vai do processo de Independência à primeira metade do século XX, a temática africana revelava-se ainda tímida na esfera governamental brasileira. Sua aparição se realizava apenas em função do interesse brasileiro pelo norte da África, onde o país, desde 1861, manti-

ciada em setembro de 1999. Em agosto de 2002, o encontro da cúpula da CPLP, em Brasília, decidiu incorporar o Timor Leste como oitavo membro oficial da Comunidade. Neste mesmo encontro, decidiu-se pela cooperação no combate à epidemia da AIDS, além da criação de mecanismos para facilitar o fluxo migratório entre os países membros.

2 Estima-se que o português seja falado por 200 milhões de pessoas, ocupando o terceiro lugar entre as línguas mais faladas no Ocidente, atrás apenas do inglês e do espanhol, sendo a sétima língua mais falada do mundo.

3 Para uma análise das relações do Brasil com a África e Portugal, ver, entre outros: Rodrigues, José Honório. Brasil e África: outro horizonte. Rio de Janeiro: Civilização Brasileira, 1961. Saraiva, José Flávio Sombra. O Lugar da África - A dimensão atlântica da política externa brasileira (de 1946 a nossos dias). Brasília: Editora da Universidade de Brasília, 1997. MourÃo, Fernando Augusto Albuquerque., \& Olivelra, Henrique Altemani de. Política africana no Brasil. In: Albuquerque, J. A. Guilhon (Org.). Sessenta anos de política externa brasileira (1930-1990): o desafio geoestratégico. São Paulo: Annablume/NUPRI/USP, 2000. (Coleção Sessenta Anos de Política Externa Brasileira (1930-1990); v. 3). GonçALves, Willams da Silva. O realismo da fraternidade. As relações Brasil-Portugal no governo Kubitschek. Tese de Doutorado, Universidade de São Paulo, São Paulo, 1994. LiNS, Álvaro. Missão Portugal. Rio de Janeiro: Civilização Brasileira, 1960. MAcHADO, Manuel de Sá Lopes. Para uma comunidade luso-brasileira. Relatório do Ministério das Relações Exteriores, 1972. 
nha instalado um consulado. ${ }^{4}$ A timidez das relações do Brasil com a África está associada à prioridade dos problemas de fronteiras na agenda externa do país após a conquista da Independência, quando "os interesses brasileiros se deslocaram, com nitidez, do Oceano Atlântico para a Bacia do Prata e a política externa se regionaliza". ${ }^{5}$ Como resultado, o Brasil "passa a concentrar sua atenção no campo da política exterior no processo de fixação de fronteiras, atendo-se ao princípio da intangibilidade das fronteiras ao tempo colonial, princípio que, anos mais tarde, já em nosso século, a Organização da Unidade Africana, em sua carta de maio de 1963, adota". ${ }^{6}$

A percepção de que a triangulação entre Brasil, Portugal e África portuguesa poderia representar uma dimensão privilegiada para a política externa brasileira emerge de forma emblemática na década de 1960, no bojo da Política Externa Independente, inaugurada pelo governo Jânio Quadros e prosseguida por João Goulart. ${ }^{7}$ Surge respaldada por debates acadêmicos que já se realizavam durante o governo Juscelino Kubitschek, ${ }^{8}$ protagonizados por intelectuais como Gilberto

4 Silva, Alberto da Costa e. O Vício da África e outros vícios. Lisboa: Edições João Sá da Costa, 1989, p. 52. Tal atitude traduzia, em grande medida, os constrangimentos externos impostos ao país pelo Tratado de Paz e Aliança entre Brasil e Portugal, pelo qual obtém, com mediação da Inglaterra, o reconhecimento da independência por Portugal, em 29/08/1825. O Tratado estabelecia, entre suas cláusulas, que não seria permitida a adesão das colônias portuguesas ao Brasil, limitando a ação do país naquele continente. Rodrigues, José Honório. Independência: revolução e contra revolução. Rio de Janeiro: F. Alves, 1975, v. 5. A política internacional, p. 149.

5 Silva, Alberto da Costa e. op. cit., p. 32.

6 Mourão, Fernando Augusto Albuquerque. \& Oliveira, Henrique Altemani de. op. cit., p. 310.

7 QuAdros, Jânio. A nova política externa do Brasil. Revista Brasileira de Política Internacional, v. 4, n. 16, outubro-dezembro de 1961.

8 Pio Pena Filho identifica que "A política externa de Kubitschek não passou completamente ao largo do processo de descolonização africano. Quando do estudo deste tema observa-se que houve, mesmo que ambígua, posição governamental a respeito do movimento". In: Döpcke, Wolfgang. (Org.) Crises e reconstruções: estudos-afro-brasileiros, africanos e asiáticos. Brasília: Linha Gráfica, 1998, p. 117. Para Williams da Silva Gonçalves, essa conduta se traduziu numa política que "procurou utilizar sua vinculação à aliança ocidental como instrumento para promover acelerado desenvolvimento industrial e evitar qualquer alteração do "status quo' nas margens do Atlântico Sul que pudessem favorecer os interesses estratégicos soviéticos". Gonçalves, Willams da Silva. op. cit., p. 369. 
Freyre, na defesa de uma comunidade luso-tropical. ${ }^{9}$ Naquele período, entretanto, a adesão do Brasil ao Tratado de Amizade e Consulta obscurecia a temática africana e a relegava à esfera das questões lusitanas. ${ }^{10}$

Ao longo da segunda metade do século XX, a dimensão africana é incorporada de forma progressiva e substancial à política externa brasileira. Associada a um discurso terceiro-mundista, inicialmente pre-

9 Ao ressaltar a importância do "mundo que o português criou"; ao propiciar, por intermédio da colonização de territórios na África, Ásia e América, o desenvolvimento e expansão do mundo ocidental, Gilberto Freyre frisava as potencialidades que o Brasil, ex-colônia, poderia vir a desenvolver perante as nações africanas sem, necessariamente, desvencilhar-se dos laços de comunhão que tinha com Portugal. Essa tese foi bastante criticada por políticos africanos que a interpretavam como uma estratégia colonialista de manutenção do status quo. A este respeito, ver: FREYRE, Gilberto. Sugestões em torno de uma nova orientação para as relações internacionais do Brasil. São Paulo: Federação das Indústrias de São Paulo, 1958. Comitinı, Carlos. A África arde. Rio de Janeiro: Codecri, 1980. GonÇALvES, Williams da Silva. op. cit., p. 133-46.

10 O "Tratado de Amizade e Consulta entre Portugal e Brasil", assinado em 16/11/ 1953, e complementado por seis acordos regulamentares, subscritos pelo presidente Juscelino Kubitschek, em 1960, fundamentava-se nos seguintes princípios: " $1^{\circ}$. Ambos os governos consultar-se-iam sempre sobre os problemas internacionais de manifesto interesse comum. $2^{\circ}$. Portugueses e brasileiros seriam equiparados em tudo que de outro modo não estivesse diretamente regulado nas disposições constitucionais dos dois países. $3^{\circ}$. Portugueses e brasileiros poderiam circular e estabelecer-se livremente nos dois países, com as únicas limitações impostas pela segurança nacional e a saúde pública. $4^{\circ}$. O tratamento da nação mais favorecida seria aplicável aos cidadãos de ambos os países". apud: MAgALHÃES, José Calvet de. Breve história das relações diplomáticas entre Brasil e Portugal. São Paulo: Paz e Terra, 1999, p. 91-2. Na interpretação de José Honório Rodrigues: "Na verdade, O Tratado de Amizade e Consulta deu ao conceito de comunidade um ar caricatural, pois comunidade é a livre associação de Estados independentes, não só com herança comum, ou similaridade jurídica, mas com uma cooperação técnica e, especialmente, fundamento econômico". Segundo a avaliação deste autor, "O Tratado é uma vitória portuguesa, arrastando o Brasil para a sua órbita, de acordo com as pretensões que citamos antes, visando a dispor de nosso apoio nas suas dificuldades internacionais. Por ele nos obrigamos consultar Portugal - com suas dependências coloniais sobre matéria internacional, tirando-nos, assim, ou pelo menos dificultando, todo o nosso jogo diplomático". RoDRiguEs, José Honório. op. cit., p. 314. Uma análise mais detalhada do Tratado pode ser vista em: GonçALVES, Williams da Silva. op. cit., p. 150-81. 
tendeu contrabalançar o peso das relações do país com os EUA e oporse às limitações impostas pela clivagem Leste-Oeste da Guerra Fria. ${ }^{11}$ Em meio ao processo de descolonização que se realizava no mundo afro-asiático, o Brasil identificava naquele Continente a possibilidade de arranjos diplomáticos capazes de lhe possibilitar um posicionamento diferenciado no cenário internacional. ${ }^{12}$

A ação brasileira para África e a política de solidariedade para com os povos do Terceiro Mundo no início da década de 1960 estão integralmente associadas a essa dimensão internacional pleiteada pelo Brasil. Enquadram-se num conjunto de ações (estabelecimento de relações comerciais e diplomáticas com os países socialistas da Ásia e da Europa, principalmente com a URSS) que buscavam a revisão das relações do país com os EUA e seu poderio hegemônico. Neste período, como afirma Amado Luiz Cervo:

As iniciativas para a África são suficientes para reconhecer o nascimento da política africana do Brasil. Ela não aconteceu sem consistência e sem cálculos estratégicos. No fundo, ela se tornou um capítulo importante na busca brasileira por novos parceiros políticos e econômicos internacionais e, ao mesmo tempo, serviu para a busca de maior autonomia no espaço das relações internacionais da época. ${ }^{13}$

11 SANTOS, Juliana Soares. CPLP: gênese e instituições. In: SARAIVA, José Flávio Sombra. (org.) Comunidade dos Países de Língua Portuguesa (CPLP): Solidariedade e ação política. Brasília: IBRI, 2001, p. 19.

12 A insurgência do processo de descolonização da África, aliada ao impacto mundial da Revolução Cubana, trouxe à tona os conceitos de neutralismo e nãoalinhamento que se traduziam, na prática, por formas alternativas de posicionamento e atuação de vários Estados diante do sistema internacional, polarizado pela disputa URSS-EUA. Esse novo posicionamento do país não se traduzirá, contudo, num comprometimento incondicional com a movimentação de outros países nessa mesma direção, em particular o Movimento dos Não-Alinhados. A respeito do conceito de neutralismo, ver: CAmPOS, Roberto de Oliveira. Sobre o Conceito de Neutralismo. Revista Brasileira de Política Internacional, ano 4, n. 14, julho de 1961. O autor distingue várias formas de neutralismo, defendendo a adoção, por fim, do que denomina neutralismo tático, que tem por objetivo: "Atingir o máximo possível de desenvolvimento econômico sem compreensão totalitária do consumo e preservação de opções democráticas".

13 Cervo, Amado Luiz. Do silêncio à afirmação: as relações do Brasil com a África. In: Cervo, Amado Luiz (Org.) O Desafio Internacional: a política exterior do Brasil de 1930 a nossos dias. Brasília: Editora Universidade de Brasília, 1994, p. 289. 
A prevalência das relações especiais do Brasil com Portugal, no entanto, dificultava a implementação de uma política de efetivo apoio aos territórios africanos em processo de independência. Para Letícia Pinheiro, a postura brasileira de apoio a Portugal nas questões relativas às colônias portuguesas:

Ainda se encontrava atrelada à retórica dos laços tradicionais de amizade à nação portuguesa, baseados na condição de excolônia e na herança cultural lusitana. Os deveres e a gratidão para com a ex-metrópole implicavam uma constante reafirmação dos vínculos e impediam a tomada de decisão que ferissem determinados propósitos do governo português. ${ }^{14}$

Somente a partir década de 1970, com o advento da Revolução dos Cravos (1974) e a independência das colônias portuguesas (19741975), ${ }^{15}$ as ações do Brasil para a África passaram a evoluir mais consideravelmente em favor da autonomia dos novos Estados e da consolidação de "relações amistosas e equânimes destes com Lisboa" ${ }^{16} \mathrm{~A}$ partir desta década, Portugal dá início ao processo de redefinição de seu papel nas relações internacionais, deslocando-se de seu relativo isolamento internacional para o processo de integração à Comunidade Econômica Européia, que se concretiza em $1985 .{ }^{17}$

Neste período, sob os governos militares Emílio Garrastazu Médice (1969-1974) e, principalmente, Ernesto Geisel (1974-1979), as relações do Brasil com as colônias portuguesas na África registram um substancial aprofundamento. Por meio da denominada política do pragmatismo responsável, o Brasil torna-se "parceiro privilegiado de países

14 PinHEIRO, Letícia. Ação e Omissão: a ambigüidade da política brasileira frente ao processo de descolonização africana, 1946-1960. Dissertação de Mestrado, Pontifícia Universidade Católica, Rio de Janeiro, 1988, p. 80.

15 As colônias portuguesas, foco principal da política externa brasileira no continente africano, foram as últimas a alcançar a independência no processo de descolonização. Através de uma política de repressão aos movimentos de libertação, Portugal prorrogou a liquidação de seu Império até 1974, quando Guiné-Bissau obteve sua independência. Na seqüência, Moçambique, Angola, Cabo Verde, São Tomé e Príncipe tornaram-se territórios autônomos.

16 Santos, Juliana Soares. op. cit., p. 21.

17 FreIXo, Adriano de. Do 25 de abril à CPLP: a inserção de Portugal nas relações internacionais contemporâneas. . Dissertação de Mestrado, Universidade do Estado do Rio de Janeiro, Rio de Janeiro, 2001. Introdução. 
africanos, em especial a Nigéria, de quem compra petróleo, países da África Austral e as ex-colônias portuguesas" ${ }^{18}$ Amado Luiz Cervo identifica que, consoante à crescente complexidade do próprio sistema internacional, as ações da diplomacia brasileira orientavam-se pela percepção de que "a África passava a ter uma relevância extraordinária. Politicamente, o continente africano era uma fonte potencial de apoio para demandas comuns no diálogo Norte-Sul, nas Nações Unidas e em outros órgãos multilaterais". ${ }^{19}$

Após ter experimentado seu apogeu nos anos 1970-80, o interesse brasileiro pelo continente africano no início da década de 1990 encontrava-se em constante e notório declínio. Analisando o período, Cervo afirma que "a crise econômica na África neste início de década é ainda mais profunda que aquela que assola a América Latina. Os mercados africanos são cada vez mais reduzidos. [...] Assim, os níveis de comércio do Brasil com a África Negra retornam aos das décadas de 1950 e 1960". ${ }^{20}$ No início da década de 1990, o comércio do Brasil com a África não chega aos $2 \%$ das relações comerciais do país, após ter alcançado níveis em torno dos $10 \%$ no início da década anterior. ${ }^{21}$

Dentro deste quadro, o surgimento e o desenvolvimento da CPLP coincide com um ciclo de retraimento das relações comerciais do Brasil com os países africanos. ${ }^{22} \mathrm{O}$ contexto atlântico apresenta-se menos relevante para a inserção internacional do país, no qual ficam para trás "os anos de ativa cooperação mútua e empreendimentos comuns sustentados na determinação do Estado brasileiro em desenvolver projetos econômicos para a África, diversificando os parceiros do comércio internacional do país". ${ }^{23}$

18 SAntos, Juliana Soares. op. cit. p. 21.

19 CERvo, Amado Luiz . op. cit., p. 308.

20 Idem., p. 320.

21 Uma análise mais detalhada das relações comerciais do Brasil com a África pode ser encontrada em: OliveirA, Henrique Altemani de. Relações comerciais BrasilÁfrica nos governos Médice e Geisel. Política e Estratégia, 1989, ano 7, n. 2.

22 Saraiva, José Flávio Sombra. op. cit., p. 217-39.

23 Idem. O Diálogo Sul-Sul e a CPLP: globalização e desigualdade no mundo pós11 de setembro (oito pontos para a reflexão). Texto apresentado no Seminário: A Comunidade dos Países de Língua Portuguesa - CPLP: Oportunidades e Perspectivas, Brasília, Itamaraty, 28-29 de maio de 2002. (mimeo). 
Para José Flávio Sombra Saraiva, esses retraimentos estão ligados não apenas à lógica das relações comerciais, mas às dificuldades de leitura "do processo decisório nacional sobre os constrangimentos internacionais que empurraram o continente africano para uma inserção recentemente marginalizada no ambiente da globalização" ${ }^{24}$ Denotam, igualmente, o processo de reorientação em que ingressa a diplomacia brasileira frente ao cenário internacional das décadas de 1980-90, marcado pelo fim da polarização estabelecida por EUA-URSS e pela imposição de um sistema internacional de caráter transitório imprevisível. Para o Brasil, este período reflete uma nova postura do país no que diz respeito à adesão a regimes internacionais e arranjos cooperativos. $^{25}$

Sua participação na CPLP, portanto, demonstra que, apesar da aparente fragilidade do relacionamento comercial afro-brasileiro, o continente africano, bem como Portugal, ainda detém uma posição

24 SARAIVA, José Flávio Sombra. CPLP: plataforma para uma frutífera concertação político-diplomática. In: Saraiva, José Flávio Sombra. (org.) Comunidade dos Países de Língua Portuguesa (CPLP): Solidariedade e ação política. Brasília: IBRI, 2001, p. 57.

25 Para vários analistas das relações internacionais do Brasil, as décadas de 1980-90 representam o período em que as diretrizes da política externa brasileira são profundamente reorientadas. Flávia Campos de Mello, por exemplo, identifica que "As principais mudanças foram observadas na área de segurança, culminando na assinatura do Tratado de Não-Proliferação Nuclear, nas relações econômicas externas, no novo posicionamento assumido nos temas do meio ambiente e dos direitos humanos, bem como no aprofundamento da integração regional. De forma geral, identifica-se uma nova postura do Brasil no que diz respeito à adesão a regimes internacionais e arranjos cooperativos”. Mello, Flávia Campos de. Regionalismo e inserção internacional: continuidade e transformação da política externa brasileira nos anos 90. Tese de Doutorado, Universidade de São Paulo, São Paulo, 2000, p. 2. Outras análises sobre a redefinição das orientações da política externa brasileira a partir da década de 1990 foram realizadas por: LiMA, Maria Regina Soares de. Política doméstica determina atuação diplomática. Carta Internacional, n. 35, janeiro de 1996. ArBilla, José Maria. A diplomacia das idéias: a política de renovação conceitual da política externa na Argentina e no Brasil (1989. 1994). Dissertação de Mestrado, Instituto de Relações Internacionais da Pontifícia Universidade Católica, Rio de Janeiro, 1997. SiLVA, Alexandra de Mello e. Idéias e Política Externa: a atuação brasileira na Liga das Nações e na ONU. Revista Brasileira de Política Internacional, ano 41, n. 2, 1998. CERvo, Amado Luiz. Os grandes eixos conceituais da política exterior do Brasil. Revista Brasileira de Política Internacional, ano 41, número especial, "40 anos", 1998. 
privilegiada para a política externa brasileira. Dentro deste processo de redefinição, tanto a África portuguesa como Portugal apresentamse como alternativas significantes e estratégicas para a diplomacia brasileira.

\section{A trajetória para a CPLP}

Será ao final do governo José Sarney (1985-1989) e durante o de Itamar Franco (1992-1994) que o projeto para constituição da CPLP irá adquirir contornos mais concretos. Uma das principais figuras deste processo será o Ministro da Cultura, José Aparecido de Oliveira, que realiza viagens aos países de língua portuguesa no esforço para a formação da Comunidade. Durante este período, contribui de forma significativa para o avanço em direção à constituição da CPLP a primeira Reunião de Chefes de Estado e de Governo dos países de língua portuguesa em São Luís do Maranhão, em 1989. Nesta ocasião, o Presidente José Sarney anuncia a Comunidade e constitui-se o Instituto Internacional de Língua Portuguesa (IILP). ${ }^{26} \mathrm{O}$ avanço mais efetivo, porém, ocorre em 1993, no governo Itamar Franco, que torna a constituição da CPLP uma prioridade, atribuindo a José Aparecido de Oliveira o cargo de Embaixador do Brasil em Portugal com a missão de concretizar a CPLP.

Posteriormente, a CPLP torna-se tema recorrente no discurso da diplomacia brasileira. Na Sessão de Abertura da Assembléia Geral das Nações Unidas em 1993, o Chanceler brasileiro, Embaixador Celso Amorim, afirma que "mais que uma forma de expressão, a lusofonia é a marca de uma atitude, de uma forma de ser e de viver, voltadas para a tolerância e convívio aberto entre vários povos". ${ }^{27}$ Neste mesmo ano, realizaram-se a I e a II Mesas-Redondas Afro-Luso-Brasileiras, no Rio de Janeiro e em Lisboa, respectivamente; sendo que a III ocorreu no início de 1994 em Luanda. Para Juliana Soares Santos, estes eventos foram "ocasiões privilegiadas para produzir momento e massa crítica

26 Com sede na Cidade da Praia, em Cabo Verde, O IILP é considerado o primeiro instrumento institucional da CPLP.

27 A Palaura do Brasil nas Nações Unidas. 1946-1995. Brasília: Fundação Alexandre de Gusmão, 1995, p. 567. 
que impulsionassem a CPLP, reuniram diplomatas, estudiosos, intelectuais, escritores e demais personalidades dos lusófonos com interesse e potencial para contribuir para o projeto". ${ }^{28}$

Em fevereiro de 1994, em Brasília, procedeu-se a reunião dos Ministros dos Negócios Estrangeiros e das Relações Exteriores dos sete países. Nesta ocasião, foi decidido recomendar aos respectivos governos a realização de uma Conferência de Chefes de Estado e de Governo para fundar a CPLP. Paralelamente, foi constituído o Grupo de Concertação Permanente, com sede em Lisboa. Este grupo, composto dos Embaixadores dos países membros, teve por objetivo a elaboração dos documentos constitutivos da futura Comunidade, bem como à organização da Conferência.

Marcada para junho de 1994, a Conferência para fundação da CPLP acabou sendo realizada em 1996, durante o governo Fernando Henrique Cardoso, que incorporou a proposta de sua criação. Apesar de até a década de 1990 a CPLP não ser um projeto prioritário do Itamaraty, estando mais ligada às figuras de José Sarney e Itamar Franco, o novo governo deu prosseguimento ao seu desenvolvimento $e$ constituição. ${ }^{29}$

Durante este processo, a CPLP foi alvo de propostas tão amplas quanto restritas. Entre as primeiras, chegou a ser projetada como organização destinada a incorporar eixos e conteúdos de designações anteriores, frutos da cultura de relações bilaterais e de relações inter-regionais dos países componentes. Entre os posicionamentos mais restritos, a CPLP foi focada na importância dos laços advindos da língua portuguesa. ${ }^{30}$ Como resultado, na fase anterior à sua institucionalização, foram restringidas tanto as propostas mais abrangentes quanto as mais limitadas. O Artigo $1 .^{\circ}$ dos Estatutos da CPLP, por consenso dos países membros, atribuiu-lhe a designação de "foro multilateral privilegiado para o aprofundamento da amizade mútua,

28 SANTOS, Juliana Soares. op. cit. p. 24.

29 O ex-Presidente Itamar Franco tornou-se Embaixador em Lisboa, ocupando o cargo até a formalização da CPLP em 1996, quando se transferiu para a Organização dos Estados Americanos, em Washington.

30 MourÃo, Fernando Augusto Albuquerque. O problema da(s) cultura(s) no limiar do ano 2000. Revista do Patrimônio Histórico e Artístico Nacional, número especial, 1999, p. 155. 
da concertação político-diplomática e da cooperação entre os seus Membros". ${ }^{31}$

A despeito da conceituação vaga $e$ imprecisa, a concepção $e$ institucionalização da CPLP exprimem um ato de vontade de sete países independentes na construção de uma organização multilateral, à semelhança da Commonwealth e da Francofonia (a esta última estão ligados Guiné-Bissau (1986), Cabo Verde (1996), São Tomé e Príncipe (1995). ${ }^{32}$ As dúvidas em torno do projeto continuam a ser, contudo, os objetivos próprios da CPLP: qual o conteúdo e as finalidades da instituição projetada? No Artigo $3 .^{\circ}$ dos Estatutos da CPLP, ${ }^{33}$ três pontos focais dão substância à definição e ao objetivo:

a) a concertação político-diplomática entre os seus Membros em matéria de relações internacionais, nomeadamente para o reforço da sua presença nos fóruns internacionais;

b) a cooperação, particularmente nos domínios econômico, social, cultural, jurídico e técnico científico;

31 Comunidade dos países de língua portuguesa. Documentos - Comunidade dos Países de Língua Portuguesa. Secretariado Executivo da Comunidade dos Países de Língua Portuguesa, 1999, 126 páginas.

32 É importante observar que estas duas comunidades têm origem ainda no processo de descolonização afro-asiático. Como interpreta Fernando Mourão: "Estas comunidades, de concepção diferente, foram estruturadas ao longo de um processo de descolonização, refletindo, portanto, modelos e processos específicos desse período. Na busca de uma definição, a Francofonia reflete a nostalgia dos laços rompidos pelas independências nacionais e a esperança de renovar os laços entre os países, de uma mesma comunidade cultural, no fundo privilegiando a cultura francesa, o que é natural, tendo em vista as condições em que foi criada. [...] Por seu turno, a Commonwealth, refletindo o pragmatismo inglês, passou por duas fases: a Commonwealth do Estatuto de Westminster, a Commonwealth das Nações, e a sua refundação na Conferência de Singapura, mantendo-se a designação de Commonwealth das Nações, agora de natureza multirracial. Os povos ainda não independentes, na passagem a estados independentes, incluíram nas suas constituições o laço com a Commonwealth, como membros livres e iguais". MourÃo, Fernando Augusto Albuquerque. Avaliação Crítica da CPLP - O Projeto, seus Mecanismos e Viabilidade Política. Texto apresentado no Seminário: A Comunidade dos Países de Língua Portuguesa - CPLP: Oportunidades e Perspectivas, Brasília, Itamaraty, 28-29 de maio de 2002, p. 2 (mimeo).

33 Comunidade dos países de língua portuguesa. Documentos - Comunidade dos Países de Língua Portuguesa. Secretariado Executivo da Comunidade dos Países de Língua Portuguesa, 1999, 126 páginas. 
c) a materialização de projetos de promoção e difusão da Língua Portuguesa.

Mais de uma década após a reunião de cúpula dos chefes dos Estados de língua portuguesa, a CPLP ainda encerra uma série de dúvidas quanto ao seu real significado. Para além da valorização e preservação dos laços étnico e histórico-culturais, qual, exatamente, o propósito deste projeto multilateral que envolve Estados de economia e bases industriais relevantes (Portugal e Brasil) com países da África portuguesa e agora também da Ásia (Timor Leste) ?34 $^{34}$

A princípio, poderia-se cogitar que o objetivo básico seria o desenvolvimento de projetos comuns, sobretudo os de âmbito culturais, consoante a harmonização da postura internacional dos países membros. Contudo, não há uma definição clara acerca dos custos deste exercício multilateral, comparativamente elevados para os países africanos e para o Timor Leste. ${ }^{35}$ Como resultado, os países africanos tem esboçado preocupação pela ausência de conteúdo político e econômico nas formulações e práticas da CPLP. Sombra Saraiva identifica que:

Dessa crítica advém um rosário de reclamações com relação à dinâmica de trabalho e aos financiamentos de projetos. Os países africanos de língua oficial portuguesa nutrem certa esperança com as possibilidades que um novo diálogo Sul-Sul poderia representar para seus projetos de desenvolvimento. Da mesma maneira, desejam enfatizar a dimensão da cooperação técnica, científica e tecnológica da CPLP bem como a vertente da concertação político-diplomática. ${ }^{36}$

34 Entre as questões econômicas que norteiam a CPLP, José Gonçalves chama a atenção para o fato de que "os países africanos de língua portuguesa estão todos classificados pela ONU entre os 48 "países menos avançados" (PMA), expressão suave para designar as economias mais atrasadas do mundo". Gonçalves. José. "Relações Econômicas e cooperação na CPLP". In: Saraiva, José Flávio Sombra. (org.) Comunidade dos Países de Língua Portuguesa (CPLP): Solidariedade e ação política. Brasília: IBRI, 2001, p. 147.

35 DöPCKE, Wolfgang. A CPLP: tanto inútil quanto necessária? Meridiano 47, n. 26, setembro de 2002, p. 23.

36 SARAIVA, José Flávio Sombra. O Diálogo Sul-Sul e a CPLP: globalização e desigualdade no mundo pós-11 de setembro (oito pontos para a reflexão). Texto 
Enfocando a perspectiva de Portugal, a CPLP constituiria-se num projeto de reafirmação internacional da língua e da cultura portuguesa. Como tal, seria um projeto vinculado aos interesses econômicos e às questões de prestígio político deste país. Protegeria a importância do Estado português através da divulgação da sua língua, revigorando, paralelamente, antigas teses sobre o "mundo que o português criou", através da expansão portuguesa no ultramar, especificamente a tese da democracia racial do colonialismo português, defendida por Gilberto Freyre. ${ }^{37}$

Ainda em relação a Portugal, a CPLP se enquadraria no processo de renegociação de seu papel no cenário internacional, através da qual, avalia Adriano de Freixo:

O Estado Português tem procurado utilizar, de forma concreta, as possibilidades geradas pelo seu pertencimento a uma Europa integrada, bem como pela herança cultural que deixou espalhada pelo mundo durante o seu período imperial. Com isto, a constituição da Comunidade dos Países de Língua Portuguesa CPLP, sob sua hegemonia, adquire uma importância estratégica para definir o seu "lugar" no mundo contemporâneo, podendo funcionar como "moeda de troca" e como trunfo político, dentro da UE e das outros organismos internacionais a que Portugal pertence. ${ }^{38}$

Para o Brasil, contudo, a adesão à CPLP ainda não está plenamente clara. Faltam elementos para demonstrar o desenvolvimento da diplomacia brasileira para a Comunidade: seus objetivos, propostas e realizações. É plenamente concebível identificar que sua participação esteja vinculada:

apresentado no Seminário: A Comunidade dos Países de Língua Portuguesa CPLP: Oportunidades e Perspectivas, Brasília, Itamaraty, 28-29 de maio de 2002. (mimeo).

37 Amaral, Ilídio do. "Sobre O Mundo que o Português Criou - Reflexões no Limiar do Século XXI". In: Seminário Internacional Novo Mundo nos Trópicos. Recife, 21 a 24 mar. 2000. Site: www.prossiga.fgf.org.br. FrEYRE, Gilberto. Sugestões em torno de uma nova orientação para as relações internacionais do Brasil. São Paulo: Federação das Indústrias de São Paulo, 1958.

38 Freixo, Adriano de. op. cit., Introdução. 
a) à manutenção de sua influência junto aos países africanos, fruto de ações diplomáticas implementadas pelo país desde a década de 1960 no continente;

b) à reafirmação da abordagem multilateral desenvolvida pela política externa brasileira no esforço de diversificação e universalização de suas relações internacionais;

c) à avaliação positiva da relação custo-benefício da triangulação entre América, Europa e África que a Comunidade ratifica.

Sob estes aspectos, a participação brasileira na CPLP faz sentido, porém limitado. Faltam elementos para compreender de forma mais clara e objetiva como a chancelaria nacional procura se apresentar frente a este Fórum. Se, a exemplo de sua atuação em outros foros internacionais, há uma preocupação por parte do Brasil em espelhar e/ou induzir a formação de políticas dos diversos atores, procurando configurar-se como ator fundamental no espaço político internacional contemporâneo e um "parceiro confiável que preza o diálogo e que tem projeção diplomática bilateral e multilateral ampla, com papel político reconhecido na América Latina e no Atlântico Sul, bem como experiência e capacidade de mobilização em vários foros". ${ }^{39}$

\section{Conclusão}

Há um consenso entre os analistas de que a política externa brasileira se orienta por um "projeto" e/ou "matriz" de ação internacional. ${ }^{40}$ Analisando as perspectivas da política externa brasileira durante

39 Barros Netto, Sebastião do Rego. O Brasil e a Rússia. In: Fonseca JR, Gelson. \& Castro, Sérgio Henrique Nabuco de. Temas de política externa brasileira. São Paulo: Paz e Terra, 1994, v. 2, p. 136.

40 Oliveiros Ferreira, por exemplo, identifica que "A política externa brasileira nunca fugiu, nos dez anos de Castello a Geisel, de algumas constantes básicas. Sua origem é comum: militar: sua fonte, comum: seguramente os estudos do Conselho de Segurança Nacional: seus fins, os mesmos: construir, com a aceleração possível, um Poder Nacional que faça do Brasil uma potência ouvida no concerto dos fortes e respeitada naquele dos fracos". FerreIRA, Oliveiros S. A política externa a serviço de uma idéia messiânica. O Estado de S. Paulo, 31/3/74, p. 29. Para 
as últimas décadas, pode-se identificar que tanto a Europa como a África constituíram-se em vertentes permanentes das relações internacionais do país. No caso das relações com a Europa, a análise realizada por Antonio Carlos Lessa apresenta uma precisa regularidade: sempre que o Brasil procura alternativas ao seu relacionamento com os EUA, volta-se para a Europa Ocidental. ${ }^{41}$ Essa conduta está diretamente associada ao processo de formulação e desenvolvimento da política externa brasileira para a África, iniciada com a Política Externa Independente: a de que o estabelecimento de alianças alternativas propicia não apenas maiores margens de manobra, como capacidade de barganha para o país no sistema internacional.

No que diz respeito à política externa brasileira para a CPLP, no entanto, faltam estudos que contemplem os marcos desta atuação $e$ esclareçam suas diretrizes. ${ }^{42}$ África e Portugal têm representado dimensões permanentes das relações internacionais do Brasil, tornando-se vertentes importantes na formulação e implementação da política externa desenvolvida pelo Estado. A partir da análise da ação diplomática brasileira para a CPLP, seria possível compreender o desenvolvimento da política externa desenvolvida pelo país no âmbito da triangulação dos continentes americano, europeu, africano e, mais recentemente, o asiático, com a incorporação do Timor Leste. Neste caso, tais estudos teriam o mérito de esclarecer, em primeiro lugar, a percepção $e$ a ação da diplomacia brasileira em relação a este foro multilateral; em segundo, verificar, no âmbito das relações internacionais, o posicionamento do Estado brasileiro em relação a Portugal, África portuguesa e Timor Leste durante a década de 1990.

A partir do mapeamento das propostas e diretrizes estabelecidas pela CPLP, seria possível identificar as ações implementadas pela Chan-

uma análise deste debate, ver, entre outros: FonSECA JR., Gelson. A legitimidade e outras questões internacionais. São Paulo: Paz e Terra, 1998, p. 293-352. Mello, Flávia Campos de. op. cit. Albuquerque, J. A. Guilhon (Org.). Sessenta anos de política externa brasileira (1930-1990): crescimento, modernização e política externa. São Paulo: Cultura - Núcleo de Pesquisa em Relações Internacionais da USP, 1996, v. 1.

41 Lessa, Antonio Carlos Moraes. A estratégia de diversificação de parcerias no contexto do nacional-desenvolvimentismo (1974-1979). Revista Brasileira de Política Internacional, ano 38, n. 1, jan-jun de 1995.

42 DöPCKE, Wolfgang. op. cit., p. 24. 
celaria brasileira, de forma a analisar o propósito da Comunidade para o quadro das relações internacionais do país durante a década de 1990. De forma correlata, apreender tanto as realizações quanto as dificuldades e dilemas enfrentados pelo Estado brasileiro em sua conduta face ao sistema internacional contemporâneo.

Tomando por hipótese que a política externa desenvolvida pelo Brasil em relação a CPLP reflete um novo padrão de relacionamento do país com Portugal e com a África Portuguesa, as ações da chancelaria brasileira para a CPLP se enquadrariam num processo de redefinição das prioridades e das parcerias estratégicas nas relações internacionais contemporâneas do país. Este processo, que se articula a mudanças ocorridas no cenário internacional ao fim da década de 1980, consolida-se na seguinte e leva à revisão da ação diplomática brasileira frente àqueles países.

A partir da análise realizada por Gerson Moura, esta hipótese identifica que a política externa brasileira para a CPLP "por um lado, acentua a necessidade de conjugar as determinações estruturais, que delimitam o campo de ação dos agentes decisores, com as determinações conjunturais, dadas pela decisão e ação dos policy-makers; por outro, repele a noção de que a política externa de um país dependente é um simples reflexo das decisões do centro hegemônico e nega também que se possa entendê-la mediante o exame exclusivo das decisões no país subordinado". ${ }^{43}$

\section{Referências bibliográficas}

A palavRA do Brasil nas Nações Unidas. 1946-1995. Brasília: Fundação Alexandre de Gusmão, 1995, p. 567.

Albuquerque, J. A. Guilhon (Org.). Sessenta anos de política externa brasileira (1930-1990): crescimento, modernização e política externa. São Paulo: Cultura - Núcleo de Pesquisa em Relações Internacionais da USP, v. 1, 1996.

Amaral, Ilídio do. Sobre o mundo que o português criou - reflexões no limiar do século XXI. In: Seminário Internacional Novo Mundo nos Trópicos. Recife, 21 a 24 mar. 2000. Disponível em: <http://www.prossiga.fgf.org.br/> .

43 MouRA, Gerson. Autonomia na dependência: a política externa brasileira de 1935 a 1942. Rio de Janeiro: Nova Fronteira, 1980, p. 43. 
ARBILLA, José Maria. A diplomacia das idéias: a política de renovação conceitual da política externa na Argentina e no Brasil (1989-1994). Rio de Janeiro, 1997. Dissertação (Mestrado) - Instituto de Relações Internacionais da Pontifícia Universidade Católica.

Barros Netto, Sebastião do Rego. O Brasil e a Rússia. In: FonseCa JR, Gelson; Castro, Sérgio Henrique Nabuco de. Temas de política externa brasileira. São Paulo: Editora Paz e Terra, v. 2, 1994.

CAmpos, Roberto de Oliveira. Sobre o conceito de neutralismo. Revista Brasileira de Política Internacional, ano 4, n. 14, julho de 1961.

CERvo, Amado Luiz. Do silêncio à afirmação: as relações do Brasil com a África. In: Cervo, Amado Luiz (Org.). O Desafio internacional: a política exterior do Brasil de 1930 a nossos dias. Brasília: Editora Universidade de Brasília, 1994.

. Os grandes eixos conceituais da política exterior do Brasil. Revista Brasileira de Política Internacional, ano 41, 1998. Especial.

Comitini, Carlos. A África arde. Rio de Janeiro: Codecri, 1980.

ComunidaDE dos países de língua portuguesa. Documentos - comunidade dos países de língua portuguesa. Secretariado Executivo da Comunidade dos Países de Língua Portuguesa, 1999, 126 p.

DÖPCKE, Wolfgang (Org.). Crises e reconstruções: estudos-afro-brasileiros, africanos e asiáticos. Brasília: Linha Gráfica, 1998.

A CPLP: tanto inútil quanto necessária? Meridiano 47, n. 26, p. 23, set. 2002.

FerreIRA, Oliveiros S. A política externa a serviço de uma idéia messiânica. $O$ Estado de S. Paulo, São Paulo, 31 mar. 1974, p. 29.

FonsECA JR., Gelson. A legitimidade e outras questões internacionais. São Paulo: Paz e Terra, 1998, p. 293-352.

FREIXo, Adriano de. Do 25 de abril à CPLP: a inserção de Portugal nas relações internacionais contemporâneas. Rio de Janeiro, 2001. Dissertação (Mestrado) - Universidade do Estado do Rio de Janeiro.

FREYRE, Gilberto. Sugestões em torno de uma nova orientação para as relações internacionais do Brasil. São Paulo: Federação das Indústrias de São Paulo, 1958.

Gonçalves, Willams da Silva. O realismo da fraternidade. As relações BrasilPortugal no governo Kubitschek. São Paulo, 1994. Tese (Doutorado) Universidade de São Paulo.

GonçaLVES. José. Relações econômicas e cooperação na CPLP. In: SARAIVA, José Flávio Sombra (Org.). Comunidade dos Países de Língua Portuguesa (CPLP): solidariedade e ação política. Brasília: IBRI, 2001. 
Lessa, Antonio Carlos Moraes. A estratégia de diversificação de parcerias no contexto do nacional-desenvolvimentismo (1974-1979). Revista Brasileira de Política Internacional, ano 38, n. 1, jan-jun. 1995.

LimA, Maria Regina Soares de. Política doméstica determina atuação diplomática. Carta Internacional, n. 35, jan. 1996.

Lins, Álvaro. Missão Portugal. Rio de Janeiro: Civilização Brasileira, 1960.

Machado, Manuel de Sá Lopes. Para uma comunidade luso-brasileira. Relatório do Ministério das Relações Exteriores, 1972.

MAGALHÃES, José Calvet de. Breve história das relações diplomáticas entre Brasil e Portugal. São Paulo: Paz e Terra, 1999.

Mello, Flávia Campos de. Regionalismo e inserção internacional: continuidade e transformação da política externa brasileira nos anos 90. São Paulo, 2000. Tese (Doutorado) - Universidade de São Paulo.

MouRA, Gerson. Autonomia na dependência: a política externa brasileira de 1935 a 1942. Rio de Janeiro: Nova Fronteira, 1980.

MourÃo, Fernando Augusto Albuquerque. Avaliação Crítica da CPLP - O Projeto, seus Mecanismos e Viabilidade Política. Texto apresentado no Seminário: A Comunidade dos Países de Língua Portuguesa - CPLP: Oportunidades e Perspectivas, Brasília, Itamaraty, 28-29 de maio de 2002. (mimeo).

O problema da(s) cultura(s) no limiar do ano 2000. Revista do Patrimônio Histórico e Artístico Nacional, 1999. Especial.

.; Oliveira, Henrique Altemani de. Política africana no Brasil. In: AlbuQUERQUE, J. A. Guilhon (Org.). Sessenta anos de política externa brasileira (1930-1990): o desafio geoestratégico. São Paulo: Annablume/NUPRI/USP, 2000. (Coleção Sessenta Anos de Política Externa Brasileira (1930-1990).

Oliveira, Henrique Altemani de. Relações comerciais Brasil-África nos governos Médici e Geisel. Política e Estratégia, ano 7, n. 2, 1989.

PINHEIRO, Letícia. Ação e Omissão: a ambigüidade da política brasileira frente ao processo de descolonização africana, 1946-1960. Rio de Janeiro, 1988. Dissertação (Mestrado) - Pontifícia Universidade Católica.

QuAdros, Jânio. A nova política externa do Brasil. Revista Brasileira de Política Internacional, v. 4, n. 16, out-dez. 1961.

Rodrigues, José Honório. Brasil e África: outro horizonte. Rio de Janeiro: Civilização Brasileira, 1961.

. Independência: revolução e contra-revolução. Rio de Janeiro: F. Alves, 1975.

SANTOS, Juliana Soares. CPLP: gênese e instituições. In: SARAIVA, José Flávio Sombra (Org.). Comunidade dos países de língua portuguesa (CPLP): solidariedade e ação política. Brasília: IBRI, 2001. 
SARAIVA, José Flávio Sombra. CPLP: plataforma para uma frutífera concertação político-diplomática. In: SARAIVA, José Flávio Sombra (Org.). Comunidade dos países de língua portuguesa (CPLP): solidariedade e ação política. Brasília: IBRI, 2001.

. O Diálogo Sul-Sul e a CPLP: globalização e desigualdade no mundo pós-11 de setembro (oito pontos para a reflexão). Texto apresentado no Seminário: A Comunidade dos Países de Língua Portuguesa-CPLP: Oportunidades e Perspectivas, Brasília, Itamaraty, 28-29 de maio de 2002. Mimeografado.

O lugar da África - a dimensão atlântica da política externa brasileira (de 1946 a nossos dias). Brasília: Editora da Universidade de Brasília, 1997.

SiLva, Alberto da Costa e. O vício da África e outros vícios. Lisboa: Edições João Sá da Costa, 1989.

SILVA, Alexandra de Mello e. Idéias e política externa: a atuação brasileira na Liga das Nações e na ONU. Revista Brasileira de Política Internacional, ano 41, n. 2, 1998. 